\title{
The Effect of Anadara granosa Shell's-Stichopus hermanni Scaffold on CD44 and IL-10 Expression to Decrease Osteoclasts in Socket Healing
}

\author{
Rima Parwati Sari ${ }^{1}$ Syamsulina Revianti ${ }^{1}$ \\ Retno Pudji Rahayu ${ }^{3}$ Sri Agus Sudjarwo ${ }^{4}$ \\ ${ }^{1}$ Department of Oral Biology, Faculty of Dentistry, Universitas Hang \\ Tuah, Surabaya, Indonesia \\ ${ }^{2}$ Department of Biomaterial, Faculty of Dentistry, Universitas Hang \\ Tuah, Surabaya, Indonesia \\ ${ }^{3}$ Department of Oral Pathology and Maxilofacial, Faculty of Dental \\ Medicine, Universitas Airlangga, Surabaya, Indonesia \\ ${ }^{4}$ Department of Pharmacology, Faculty of Veterinary Medicine, \\ Universitas Airlangga, Surabaya, Indonesia
}

Dwi Andriani ${ }^{1} \quad$ Widyasri Prananingrum²

Address for correspondence Rima Parwati Sari, DDS, MDS, PhD, Departement of Oral Biology, Faculty of Dentistry, Universitas Hang Tuah, Jln. Arief Rachman Hakim No. 150, Surabaya 60111, Indonesia (e-mail: rima.parwatisari@hangtuah.ac.id).

Eur J Dent 2021;15:228-235

\section{Abstract \\ Keywords \\ - Anadara granosa shell \\ - Stichopus hermanni \\ - hyaluronic acid \\ - CD44 \\ - IL-10 \\ - osteoclast \\ - socket healing}

Objectives This article aimed to investigate the effect of Anadara granosa (AG) shell's-Stichopus hermanni scaffold on cluster of differentiation (CD)44 and interleukin-10 (IL-10) expression to decrease osteoclasts in socket healing.

Materials and Methods Thirty male Wistar rats were divided into five groups. The lower left incisor was extracted, then given a placebo for group control (K), the treatment group was administered with scaffold from AG shells, and a treatment group with scaffold from blood cockle shell-S. hermanni with the concentration of $0.4,0.8$, and 1.6\% (AGSH0.4; AGSH0.8; AGSH1.6). We made a bone graft from a combination of AGSH extract using the freeze-dried method. The socket was sutured by silk braid immediately. Third and Seventh days postextraction, animals are killed. CD44 and IL-10 expression were examined with immunohistochemistry, as well as osteoclast was examined with hematoxylin-eosin.

Statistical Analysis The data were analyzed using a one-way analysis of variance (for CD44 and osteoclast) and Kruskal-Wallis' test (for IL-10) followed by a post hoc test in which the result of $p<0.05$.

Results Scaffold from a combination of AGSH increased CD44 expression significantly, which enhanced IL-10 expression thereby decreased the number of osteoclasts in socket healing on days 3 and 7.

Conclusion Scaffold of AG shell-S. hermanni with a concentration of $0.8 \%$ was effective to enhance CD44 and IL-10 expression to decrease osteoclast in socket healing after tooth extraction.

\section{Introduction}

Tooth extraction is one of the most common treatments. Generally, healing will occur even without intervention. However, this condition often causes certain circumstances

published online January 28, 2021
DOI https://doi.org/ $10.1055 / \mathrm{s}-0040-1719215$ ISSN 1305-7456. and constant hard pressure that makes the ability of the bones to adapt becomes low and intolerant. Based on studies conducted by Van der Weijden, the loss of alveolar bone in the horizontal dimension is higher than the loss in the vertical dimension. ${ }^{1}$ Besides, postextraction complications due to

(c) 2021. European Journal of Dentistry.

This is an open access article published by Thieme under the terms of the Creative Commons Attribution-NonDerivative-NonCommercial-License, permitting copying and reproduction so long as the original work is given appropriate credit. Contents may not be used for commercial purposes, or adapted, remixed, transformed or built upon. (https://creativecommons.org/licenses/by-nc-nd/4.0/)

Thieme Medical and Scientific Publishers Pvt. Ltd., A-12, 2nd Floor, Sector 2, Noida-201301 UP, India 
considerable trauma may cause damage to the alveolar bone in the tooth concerned. ${ }^{2}$

After the tooth extraction, the alveolar bone will undergo the healing process. The inflammatory response after trauma/injury plays an important role, both in normal and pathological healing. Inflammation of periodontal tissues that secrete macrophages produces several mediators of cell signaling. Macrophages are a key player in the regeneration process which involves phagocytosis, presentation of antigens, and secretion of various cytokines, chemokines, and growth factors that protect the body from inflammation. ${ }^{3}$

At the beginning of inflammation, M1 was found characterized by cytokine production of tumor necrosis factor- $\alpha$ (TNF- $\alpha$ ), interleukin-1 (IL-1), and interleukin-6 (IL-6), whereas at the next stage, M2 was found, marked by the appearance of anti-inflammatory cytokines such as interleukin-10(IL-10), interleukin-4(IL-4), and interleukin-13 (IL-13). ${ }^{3}$ Proinflammatory cytokine products, such as IL-6, IL-1, and TNF- $\alpha$, can induce increased regulation of the receptor activator of nuclear factor-B ligand (RANKL) expressed by osteoblasts. ${ }^{4,5}$ RANKL, which binds to RANK, is signaled by preosteoclasts which lead to osteoclast activity in bone resorption. ${ }^{6}$ This can be offset by the presence of IL-10 which is an anti-inflammatory cytokine that modulates alveolar bone homeostasis that increases osteoblast production. ${ }^{7}$

In the field of dentistry, the use of bone grafts begins to increase. Bone graft base material refers to hydroxyapatite (HA) material which is a major inorganic component of hard bone tissue and accounts for 60 to $70 \%$ of mineral phases in human bones. The combination of HA-tricalcium phosphate (TCP) can be used as a bone replacement because it is biocompatible, can increase new bone formation, and through the effects of osteoconduction can increase bone mass in the area of the defect. ${ }^{8}$ TCP has a stoichiometry similar to an amorphous bone precursor, whereas HA has a stoichiometry similar to bone mineral. ${ }^{9}$ One of the natural ingredients that have the potential to be used as a candidate for bone substitute material is the shell of blood clams (Anadara granosa [AG]), which can be synthesized into HA and TCP forms. A study conducted by Kresnoadi et $\mathrm{a}^{10}$ showed the role of bone graft (bovine bone graft) in increasing Hsp70 on day 3 and osteocalcin expression on day 7 , resulting in accelerated osseointegration.

The polymer material is added to the bone graft structure because the material is needed to increase the smelting ability into the remodeling process. Among the most widely used polymeric materials is hyaluronic acid. Hyaluronic acid is a natural material, hydrophilic, and nonimmunogenic, and found in the cytoplasm of osteoprogenitor cells. ${ }^{11} \mathrm{~A}$ study using hyaluronic acid with a concentration of $0.8 \%$ states that hyaluronic acid accelerates bone regeneration by chemotaxis, proliferation, and mesenchymal cell differentiation. ${ }^{12}$

Cell response variation due to hyaluronic acid induction is the proliferation, migration, and synthesis of cluster of differentiation (CD)44-mediated cytokines present on the cell surface. Hyaluronan induces a receptor-mediated signal by interaction with a hyaluronic acid-binding protein on the cell surface. The interaction of hyaluronic acid with
CD44 induces the grouping of CD44 receptors and activation of mitogen-activated protein kinase (MAPK) regulated by intracellular receptor for hyaluronan-mediated motility, resulting in phosphorylation of extracellular signal-regulated protein kinases $1 / 2$ (ERK1/2) and activation of activator protein-1 (AP-1) transcription and the nuclear factor-кB. ${ }^{13,14}$ The golden sea cucumber (Stichopus hermanni) is a natural material that has not been explored, especially in the field of dentistry. One area that produces many S. hermanni is Raas Island in Sumenep Regency. Test characterization of glycosaminoglycans (GAGs) content on S. hermanni with spectrophotometer showed that it mostly (75.7\%) contained hyaluronic acid. ${ }^{15}$ Therefore, it is necessary to study the application of granules from AG shells and S. hermanni in concentrations of $0.4,0.8$, and $1.6 \%$ and the mechanisms for alveolar bone healing after tooth extraction.

\section{Materials and Methods}

\section{Preparation of HA-TCP Powder}

The study preparation began with the making of a graft from the blood clam (AG) shell which was synthesized into the HA-TCP form. The shell was boiled for 30 minutes and cleaned. After that, the shell was crushed using mortar and paste and was sieved with 100 mesh to obtain smaller particle yields. Next, $\mathrm{Ag}$ shell powder as much as $1 \mathrm{M}$ and $\mathrm{NH}_{4} \mathrm{H}_{2} \mathrm{PO}_{4} 0.6 \mathrm{M}$ solution were mixed with a magnetic stirrer for 30 minutes and transferred to the reactor. The reactor was fed into an electric oven to be heated to $200^{\circ} \mathrm{C}$ for 12 hours. The results obtained were cooled at room temperature. Subsequently, the heated powder was washed with distilled water using magnetic stirrers repeatedly until the reaction results were separated from the distilled water, indicated by the $\mathrm{pH}$ that returned to 7. The last washing was performed with methanol to limit the agglomeration of HA particles during drying. The samples were dried in an electric oven at $50^{\circ} \mathrm{C}$ for 4 hours. Sample sintering was performed at $900^{\circ} \mathrm{C}$ for 3 hours to remove impurities and increase sample crystallinity. ${ }^{16}$

\section{Preparation of Stichopus hermanni Powder}

Preparation of S. hermanni material was done by washing the sea cucumber with sterile distilled water, then prepared to blend with the ratio of sea cucumber:sterile distilled water of $500 \mathrm{~g}: 1 \mathrm{~L}$, until a smooth consistency was obtained. Furthermore, sea cucumbers were dried by the freeze-drying method. The freeze-drying results were finely ground and sieved with a mesh of size 50 (297 microns). The conversion into the microsize required High Energy Milling Elliptical 3D Motion (HEM-E3D) by Nanotech Indonesia. ${ }^{17}$

\section{Preparation of Anadara granosa Shell's-Stichopus hermanni Scaffold}

The next step was the making of the scaffold with the freeze-drying method. First, we made an HA-TCP solution obtained from $5 \mathrm{~g}$ of a blood clamshell (AG), dissolved in $50 \mathrm{~mL}$ distilled water $(10 \mathrm{w} / \mathrm{v})$. Subsequently, polymers were prepared by dissolving $10 \mathrm{~g}$ of gelatin into $50 \mathrm{~mL}$ of distilled water $(20 \mathrm{w} / \mathrm{v})$. For AG shell-S. hermanni (AGSH) 
groups of combination, the two solutions were mixed with a $1: 1$ ratio and stirred with a magnetic stirrer for 4 hours and fed into a 96-well plates mold and fed into the freezer of $-80^{\circ} \mathrm{C}$ for at least 10 hours and dried using the freeze-drying method. The final stage of this scaffold making was sterilization by gamma-ray irradiation of $25 \mathrm{kGy}$ by BATAN. ${ }^{18}$

\section{Preclinical Test to the Experimental Animals}

The research was then conducted following approval from the Ethical Commission for Animal Subjects Faculty of Dental Medicine, Universitas Airlangga, Surabaya No. 002/HRECC.FODM/I/2018. Animal trials started with the acclimatization of the Wistar rats for 7 days. Before being divided by group, the experimental animals were weighed and marked. The animals were fasted overnight before being anesthetized. Anesthesia was performed using a Ketamine $10 \%$ (Kepro pharmaceuticals, Holland) with a dose of $0.1 \mathrm{~mL} / \mathrm{kg}$ body weight (BW) and Xyla (Interchemie, the Netherlands) with $0.01 \mathrm{~mL} / 100 \mathrm{~g}$ BW on the upper right thigh intramuscularly. ${ }^{19}$ Thereafter, the cleaning was performed in the extraction area with water spray and antiseptic fluid to make the extraction area aseptic. Then, the extraction of the lower left mandibular incisive tooth in the rats was performed using needle holders and scaffold applications. The application of the treatment materials was done by dividing 30 male rats into five groups. The control (K) group was only applied with gelatin, the AG group was applied with a scaffold from the AG shell alone, and the AGSH0.4; AGSH0.8; AGSH1.6 group was applied with scaffold from the combination of AGSH with concentrations of $0.4,0.8$, and $1.6 \%$. Suturing was done to close the sockets using silk braid (USP 3/0) DR. SELLA (Bekasi, Indonesia). Analgesics of Novalgin (Sanofi Aventis, Jakarta, Indonesia), $0.09 \mathrm{~mL} / 200 \mathrm{~g} \mathrm{BW}$, and Interflox (Interchemie, the Netherlands), $0.1 \mathrm{~mL} / 100 \mathrm{~g}$ BW, antibiotics were needed to control swelling and pain.

\section{Histological Study}

Three and seven days after the application on the socket, the animals were killed and the mandibular preparation was taken and fed into a 10\% formaldehyde buffer solution to prevent the tissue from decomposing, tissue hardening, increasing the refractive index of various tissue components, and increasing the affinity of the tissue against the stain. After the process of tissue fixation, the process of decalcification was done using EDTA for 1 month. Mandibular specimens were prepared in the form of transversal preparations with hematoxylin-eosin and immunohistochemical staining with monoclonal anti-CD44 (ab25340, Abcam, United States) and monoclonal anti-IL-10 (ab189392, Abcam). After that, we observed the number of blood vessels and the number of macrophage cells reacted positively to anti-CD44 and anti-IL-10 in the socket with a light microscope (Olympus CX21, Japan) at 100 and 400 magnification. Furthermore, data tabulation and statistical analysis were conducted with one-way analysis of variance followed by the Tukey's honestly significant difference (HSD) test.

\section{Results}

Observation of CD44 Expression in the Healing Socket

Data on CD44 positive expression were obtained from macrophage observations in $2 / 3$ apical sockets in each group. CD44-exposed macrophages showed a positive reaction in the brown stain of the cytoplasm, indicating CD44 antigen reaction with anti-CD44. The result of observation using a light microscope in 400 magnification is shown in - Fig. 1.

The result of multiple comparison, Tukey's HSD test, is shown in - Table 1. Based on treatment type on day 3, the expression of CD44 between the Kgroup and the group receiving AG shell only showed a significant difference compared with the group receiving a combination of AGSH. Among the AGSH groups alone, there was a significant difference in CD44 expression between groups receiving a combination of AGSH 0.4\% (AGSH0.4) and 1.6\% (AGSH1.6) with groups receiving a combination of AGSH 0.8\% (AGSH0.8). The same findings were also found on day 7 treatment. Differences were found in the AGSH0.4 group with AGSH1.6, whereas in the 3-day treatment, multiple comparison, Tukey's HSD test, showed

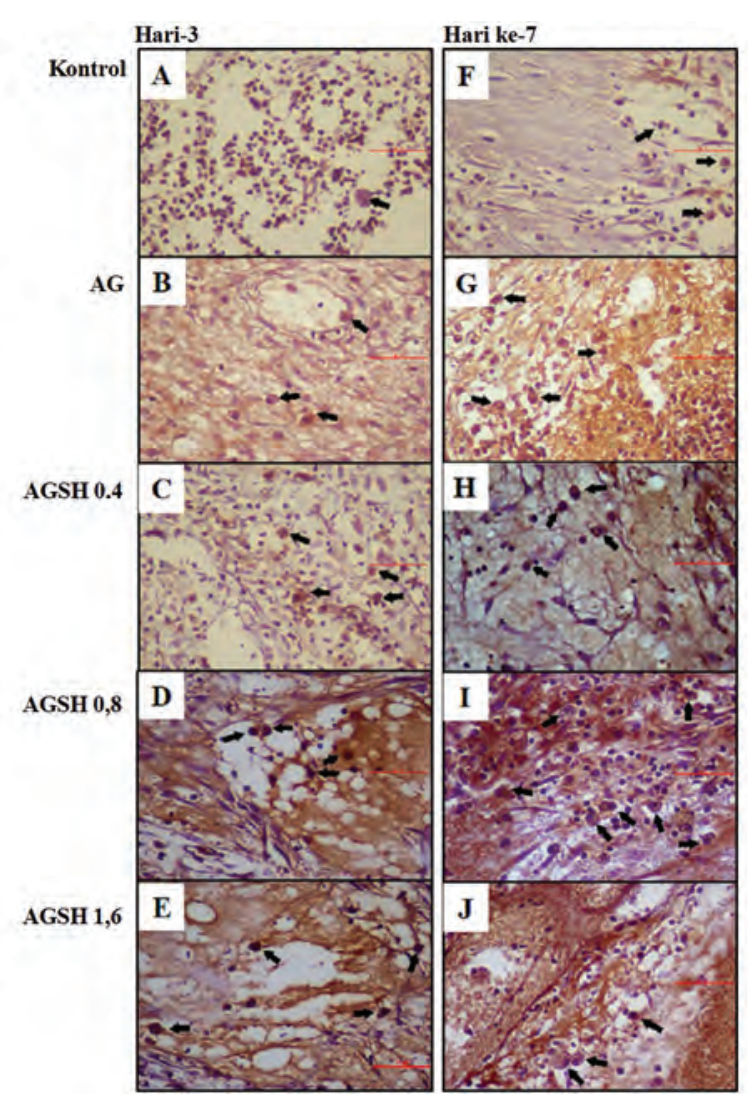

Fig. 1 Histological section of CD44 expression with application of bone graft from AGSH combination in 2/3 socket apical after tooth extraction. Pathological conditions in control group ( 3 days $=\mathrm{A}$ and 7 days $=$ B) showed that CD44 expression on macrophages. CD44 expression on macrophages has increased in the application of bone graft from the AG shell (C, D); AGSH0.4 (E, F); AGSH0.8 (G, H); AGSH1.6 (I, J). Staining of IHC with anti-CD44 monoclonal. Observation using a light microscope at 400 magnification. AG, Anadara granosa; AGSH, Anadara granosa shell and Stichopus hermanni; CD, cluster of differentiation; IHC, immunohistochemical. 


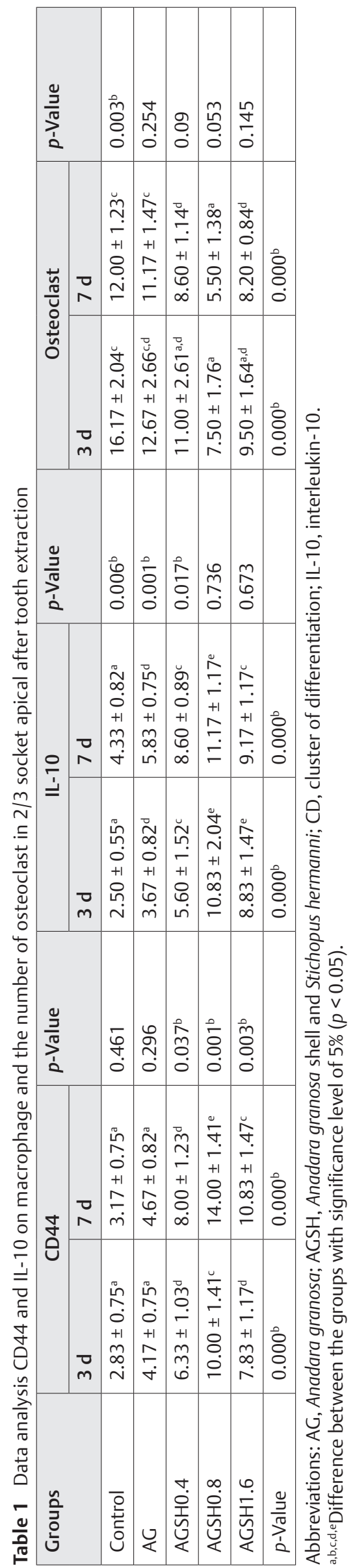

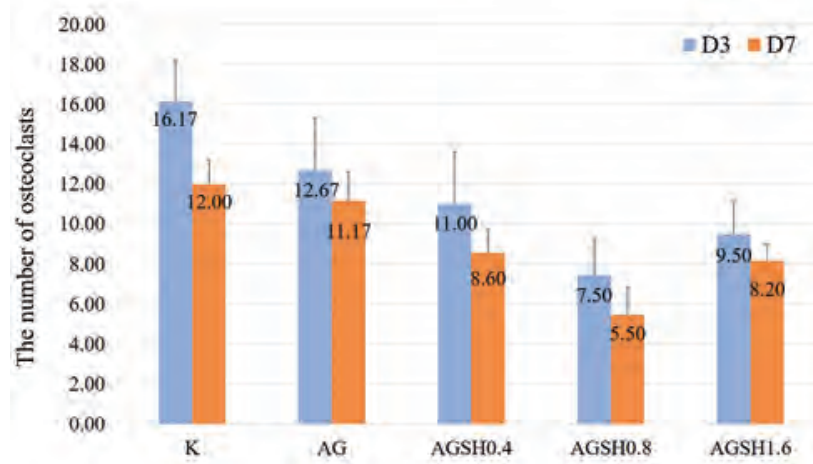

Fig. 2 CD44 expression after application bone graft from AGSH combination in 2/3 socket apical. CD44 expression in the control group (C) was seen on 3 days and increase on 7 days. While CD44 expression on AG shell treatment group on 3 days were more than those on control group, and they were increased on 7 days. Application bone graft in other groups (AGSH0.4; AGSH0.8; AGSH1.6) was increased of CD44 expression on macrophages. The highest CD44 expression on macrophages was found in the 0.8 AGSH group both on 3 and 7 days. AG, Anadara granosa; AGSH, Anadara granosa shell and Stichopus hermanni; CD, cluster of differentiation.

no significant difference between AGSH0.4 and AGSH1.6. However, on day 7 treatment, there was a significant difference between AGSH0.4 and AGSH1.6. This suggests that the increase in CD44 expression in the AGSH1.6 group was higher than in the AGSH0.4 group on day 7 (-Fig. 2).

The result of the $t$-test showed that in the combination group of AGSH, there was a significant difference between treatment duration of 3 and 7 days, whereas groups $K$ and AG did not show any significant difference. This suggests that the AGSH group tended to increase CD44 expression, which did not occur in $\mathrm{K}$ and AG groups. The highest increase occurred in the group receiving a combination of AGSH0.8, which on day 3 showed the highest CD44 expression compared with other groups, and this continued to occur until day 7.

\section{Observation of IL-10 Expression in the Healing Socket}

Data on IL-10 positive expression were obtained from macrophage observation on 2/3 apical sockets in each group. Macrophages expressing IL-10 showed a positive reaction in a brown stain of the cytoplasm, showing the reaction of IL-10 antigen with anti-IL-10. The result of observation using a light microscope with 400 magnification is shown in - Fig. 3 .

The group with the highest IL-10 expression was the group receiving a combination of AGSH in a concentration of $0.8 \%$ (AGSH0.8), while the lowest was in the $\mathrm{K}$ group. Increased expression of IL-10 on day 7 was higher than that on day 3. The group with the addition of S. hermanni (AGSH) showed higher IL-10 expression than the K and AG shell groups ( - Fig. 4).

The results of the multiple comparison, Mann-Whitney's test, are shown in - Table 1 . Based on the treatments, the expression of IL-10 in group $\mathrm{K}$ was significantly different from that in the AG group and AGSH combination group. Significant differences were also seen between AG and AGSH groups. Among the AGSH groups alone, significant differences were seen between AGSH0.4 groups with AGSH0.8 and AGSH1.6 groups. The only significant difference was shown between AGSH0.8 and AGSH 1.6 groups. The same was also found on day 7 treatment. On day 


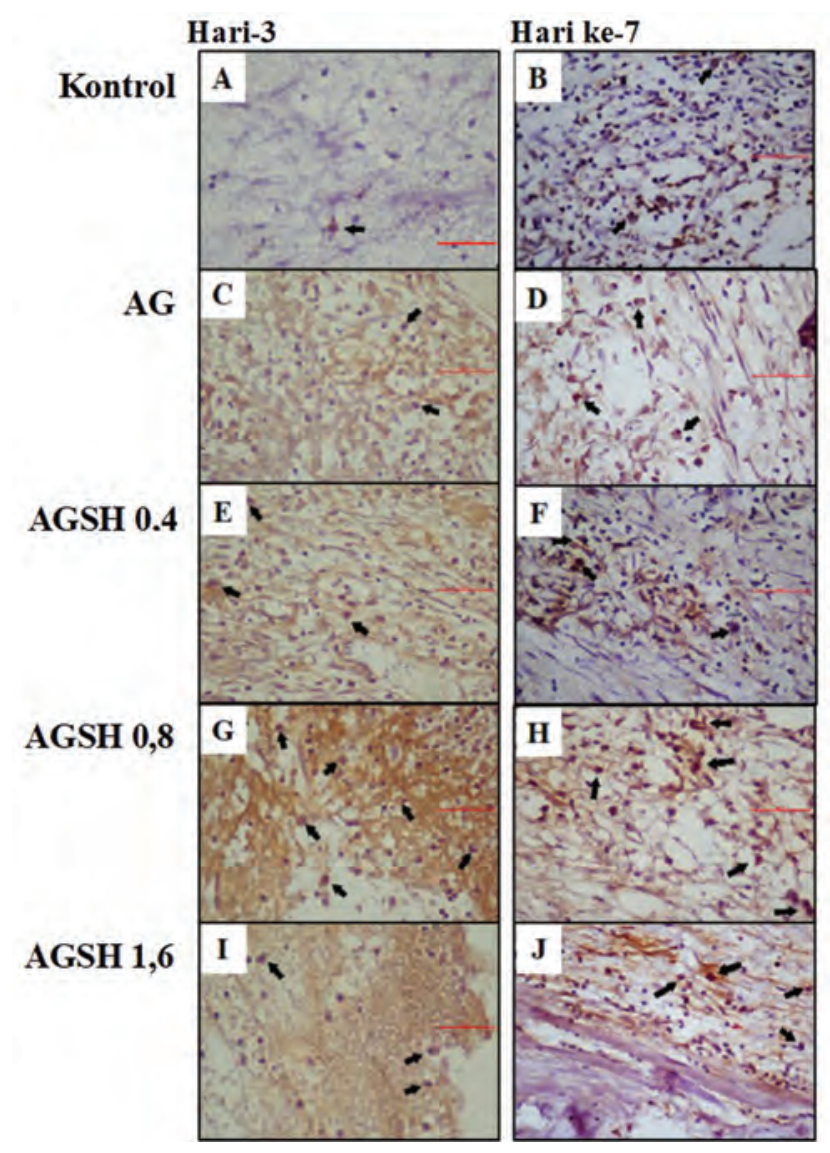

Fig. 3 Histological section of IL-10 expression with application of bone graft from AGSH combination in 2/3 socket apical after tooth extraction. Pathological conditions in control group (3 days $=\mathrm{A}$ and 7 days $=$ B) showed that IL-10 expression on macrophages. IL-10 expression on macrophages has increased in the application of bone graft from the AG shell (C, D); AGSH0.4 (E, F); AGSH0.8 (G, H), but decrease again in AGSH1.6 (I, J). Staining of IHC with anti-IL-10 monoclonal. Observation using a light microscope at 400 magnification. AG, Anadara granosa; AGSH, Anadara granosa shell and Stichopus hermanni; IHC, immunohistochemical; IL-10, interleukin-10.

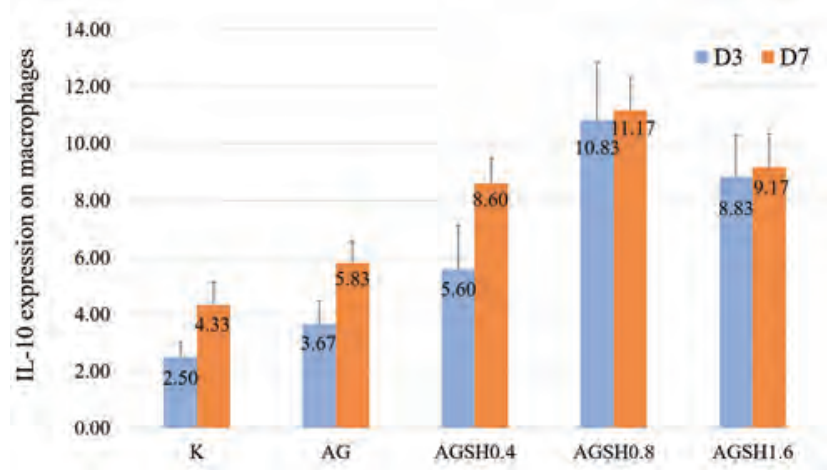

Fig. 4 IL-10 expression after application bone graft from AGSH combination in 2/3 socket apical. IL-10 expression in the control group (C) was seen on 3 days and increase on 7 days. While IL-10 expression on AG shell treatment group on 3 days were more than those on control group, and they were increased on 7 days. Application bone graft in other groups (AGSH0.4; AGSH0.8; AGSH1.6) was increased of IL-10 expression on macrophages. The highest IL-10 expression on macrophages was found in the 0.8 ACSH group both on 3 and 7 days. AG, Anadara granosa; AGSH, Anadara granosa shell and Stichopus hermanni; IHC, immunohistochemical; IL-10, interleukin-10.

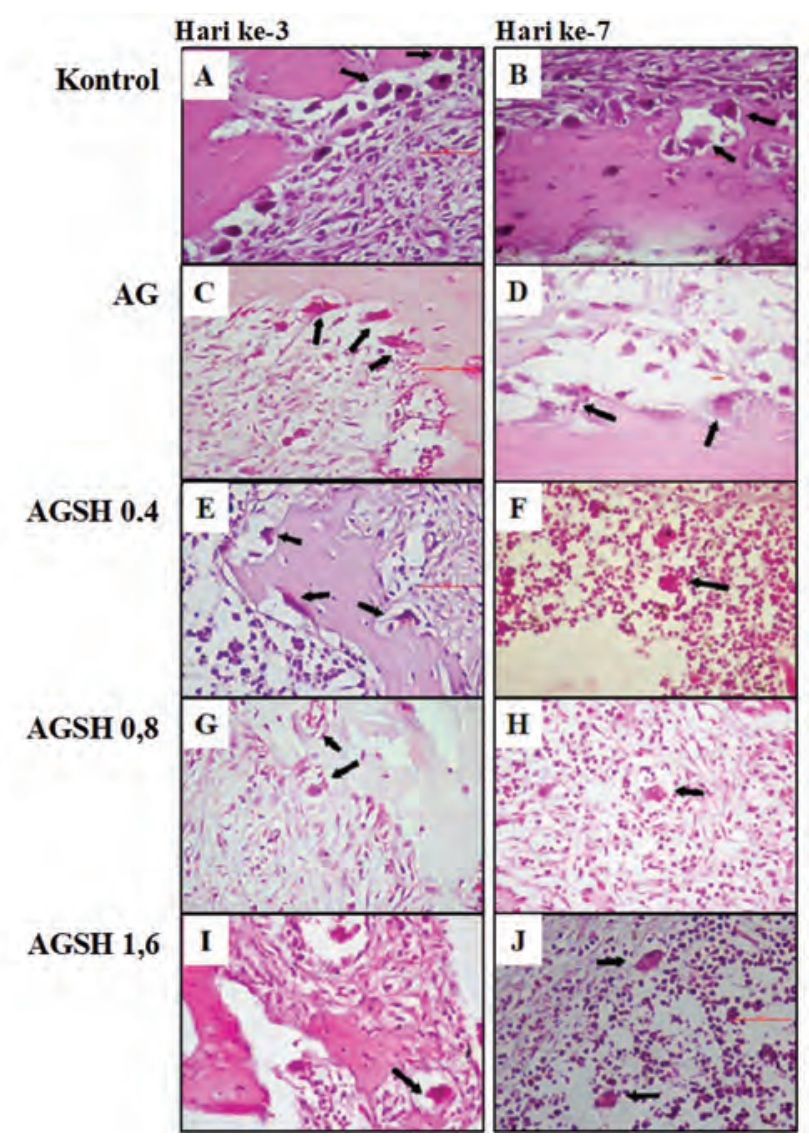

Fig. 5 Histological section of osteoclast with application of bone graft from AGSH combination in 2/3 socket apical after tooth extraction. Pathological conditions in control group ( 3 days $=\mathrm{A}$ and 7 days $=\mathrm{B}$ ) showed that a lot of osteoclast on macrophages. The number of osteoclast on macrophages has decreased in the application of bone graft from the AG shell (C, D); AGSH0.4 (E, F); AGSH0.8 (G, H); AGSH1.6 (I, J). Staining of haematoxylin eosin (HE). Observation using a light microscope at 400 magnification. AG, Anadara granosa; AGSH, Anadara granosa shell and Stichopus hermanni.

7 treatment, significant differences occurred between AGSH0.8 and AGSH1.6, but between AGSH0.4 and AGSH1.6, there was not any significant difference.

Multiple comparison, Mann-Whitney's test, results based on treatment duration between days 3 and 7 indicated that significant differences occurred between K, AG, and AGSH0.4 groups. This shows that the combination group, AGSH0.8 and AGSH1.6, showed improvement since day 3 and relatively stable on day 7 , while the other group did not.

\section{Osteoclasts Count in Alveolar Bone after Tooth Extraction}

Data on osteoclast count were obtained from observations on histopathologic sections of $2 / 3$ apical socket with HE staining and 400 magnification. The result of observation using a light microscope with 400 enlargement is shown in -Fig. 5. The mean description indicated that the $\mathrm{K}$ group had the highest osteoclast count, while the lowest was in the group receiving the combination AGSH0.8. The increase in osteoclast count on day 7 was lower than day 3 in each treatment group. The AGSH combination group showed lower osteoclast count than the $\mathrm{K}$ group and AG group (-Fig. 6). 


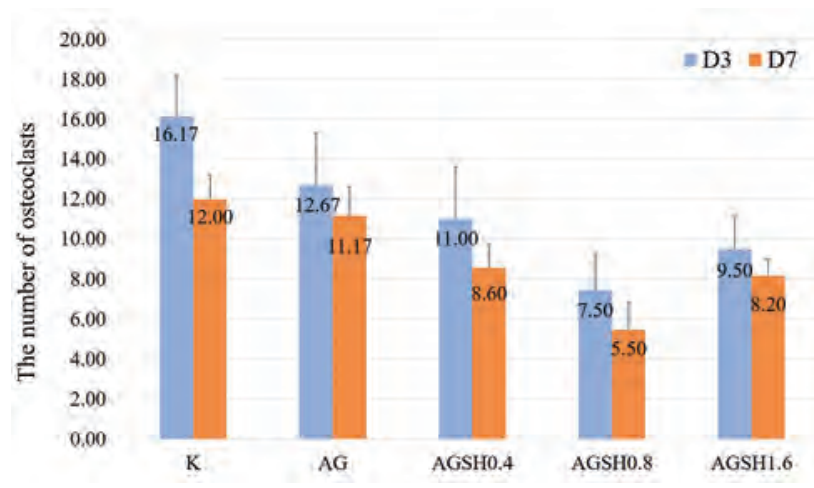

Fig. 6 The number of osteoclast after application bone graft from AGSH combination in 2/3 socket apical. The number of osteoclast in the control group (K) was seen on 3 days and decrease on 7 days. (point) The osteoclast on AG treatment group was less than those on control group, and they were decreased on 7 days. However, in other treatment groups (AGSH0.4; AGSH0.8; AGSH1.6), the decrease of osteoclasts number was shown. The lowest number of osteoclasts was found in the $0.8 \mathrm{AGSH}$ group both on 3 and 7 days. AG, Anadara granosa; AGSH, Anadara granosa shell and Stichopus hermanni; CD, cluster of differentiation.

The result of multiple comparisons, Tukey's HSD test, in - Table 1, based on treatment type on day 3, showed significant differences between the K group with AGSH combination group and AG group with AGSH0.8 group. The nonsignificant differences were found in the AG group with K, AGSH0.4, and AGSH1.6 groups, and AGSH0.8 group with the AGSH0.4 and AGSH1.6 groups.

Results of multiple comparison, Tukey's HSD tests, based on treatment type on day 7 showed significant differences between K and AG groups with all AGSH combination groups, AGSH0.8 groups with AGSH0.4 and AGSH1.6 groups. The difference was not significant between AG and $\mathrm{K}$ groups, and AGSH0.4 with AGSH1.6 groups. Based on the duration of treatment of 3 and 7 days, significant differences were seen only in the K group, while the other groups did not show any significant differences.

\section{Discussion}

In the normal healing process of alveolar bone after tooth extraction, an increase in inflammation occurs characterized by the migration of inflammatory cells. Macrophages are a key factor in regulating the signaling transduction of tissue repair processes. Macrophages produce monocyte chemoattractant protein (MCP)-1. Increased levels of MCP-1 expression stimulate macrophage infiltration and MCP$1 / \mathrm{C}-\mathrm{C}$ chemokine receptor type 2 interactions will improve adhesion and mesenchymal stem cell (MSC) migration. CD44 is also another important adhesion molecule. The interaction of CD44-hyaluronic acid is essential for extravasation in inflammatory sites. Besides, CD44-hyaluronic acid interactions also increase the adhesiveness and motility of MSCs. ${ }^{20}$ Under normal conditions, hyaluronic acid is present in the bloodstream with a low concentration and will increase rapidly in the wound area. ${ }^{21}$ This can be seen in the $K$ group which underwent extraction. In the treatment group receiving the bone graft, HA-TCP from the synthesis of AG shell, the increase of CD44 expression did not show a significant difference with the K group ( $p>0.05$ ). This suggests that HA-TCP from the synthesis of AG shells did not significantly affect the increase in CD44 expression.

All bone graft groups from a combination of AGSH (0.4$1.6 \%$ concentrations) showed significant differences compared with the K group and AG alone $(p<0.05)$. This shows the role of $S$. hermanni (sea cucumber) is very significant in the increase of CD44 expression in macrophage cells.

The hyaluronic acid content of $S$. hermanni can increase interaction with CD44. This interaction can induce activation of MAPK and result in phosphorylation of ERK1/2 and activation of AP- 1 transcription. Active transcription of AP- 1 target genes induces a transduction pathway that results in the induction of cell migration with the release of various growth factors. ${ }^{13,14}$

The difference in concentration of whole S. hermanni was also influential in interaction with CD44. This was demonstrated by a significant difference between the 0.4 and $0.8 \%$ concentrations, whereas whole $S$. hermanni with a $0.8 \%$ concentration showed a higher increase of CD44 expression and multiple comparison test results showed significant differences $(p=0.05)$. The higher the total $S$. hermanni concentration, that is, at $1.6 \%$ concentration, the more significant the decrease in CD44 expression in the macrophages than the concentration of $0.8 \%$. This is because $S$. hermanni contains other GAGs, such as chondroitin sulfate and keratin sulfate, which may affect CD44's ability to bind hyaluronic acid. Binding modification occurs because the $\mathrm{N}$ and $\mathrm{O}$ chains in chondroitin sulfate have a negative effect on CD44's ability to bind hyaluronic acid. ${ }^{22}$

Different treatment times resulted in increased CD44 expression. This was seen in all treatment groups experiencing an increase in CD44 expression on observation day 7. The tendency of CD44 to bind hyaluronic acid varies greatly across cell types. Some of the regulatory mechanisms of hyaluronic acid binding on CD44 have been conceptualized. One type of mechanism relates to the fact that hyaluronan molecules, based on their repetitive structures (GlcNAcß1-4GlcUA), contain multiple CD44 binding sites. Each hyaluronic acid chain can interact simultaneously with many receptors on the cell surface. In addition, changes in CD44 density and set on the cell surface can affect the overall strength or avidity of the multivalent interactions. Another mechanism that can occur is a change in the conformational state of hyaluronic acid through the formation of protein macromolecular complexes or differences in the length of hyaluronic acid chain that can affect the binding of hyaluronic acid and its functional consequences. ${ }^{23}$

Macrophages are key regulators of the regeneration and activation process of various pro- and anti-inflammatory cytokines, chemokines, and growth factors that also play a role in the healing process. ${ }^{24}$ In early inflammation, many M1 phenotypes are found, which are characterized by the abundance of proinflammatory cytokine products. Furthermore, there is polarization to $\mathrm{M} 2$, which is characterized by anti-inflammatory cytokine products and growth factors. IL-10 is one of the anti-inflammatory cytokines secreted by macrophages via the M2 subphenotype. IL-10 may inhibit 
the production of proinflammatory cytokines, such as TNF- $\alpha$, IL-1, and IL-6. ${ }^{3}$ The presence of IL-10 occurs on day 3 following trauma events, and the expression is limited on days 7 to $10 .^{25,26}$ This was demonstrated in the results of this study, where on day 3, the IL-10 expression was found in the K group and AG group and the Gomes-Howell's test showed no significant difference. Increased expression of IL-10 on day 7 was higher than that on day 3 and the $t$-test showed significant differences.

The hyaluronic acid present in the whole $S$. hermanni can interact strongly with CD44 receptors that have contributed to the retention of these cells at the site of the inflammation. ${ }^{27}$ Ha binding with CD44 could inhibit the contact between Toll-like receptor 4 and myeloid differentiation primary response 88 which results in NF- $\mathrm{k} \beta$ inhibition, thus it reduces proinflammatory activation; however, there was an elevation in IL-10 expression in macrophages. ${ }^{28,29}$ A higher increase in the expression of IL-10 was demonstrated in the group receiving bone graft from the combination of AGSH than the K group and the group receiving bone graft from the AG shell alone.

Increased expression of CD44, which is a receptor binding to hyaluronic acid, is highly influential in increased IL-10 expression. Therefore, decreased CD44 expression will have an impact on the decreased expression of IL-10. This occurred in groups receiving bone graft from a combination of AGSH with concentrations of 0.4 and $1.6 \%$.

In the group receiving bone graft from the combination of AGSH with concentrations of 0.8 and $1.6 \%$, the increased expression of IL-10 on day 3 was high, so the IL-10 expression on day 7 did not experience a significant increase. This was because the inflammatory inhibition process had been started since the beginning and it was assumed that the healing process had also started earlier so that on day 7 of the inflammation process, it has decreased and the proliferation process has dominated. In contrast to the $0.4 \% \mathrm{~S}$. hermanni concentration, this group still showed a significant increase in IL-10 expression on day 7.

At the time of the inflammatory phase, macrophages release proinflammatory cytokines, such as TNF- $\alpha$, IL-1, IL-6, also known as proinflammatory cytokines, potentially as stimulators of RANKL formation in osteoblasts. When binding to RANKL, preosteoclasts expressing RANK will activate osteoclasts that function to resorb the bone resulting in the appearance of defects. ${ }^{30}$ This was seen in the results of this study, which in the K group, the number of osteoclasts was higher than that in other groups and the statistical tests found significant differences. In normal healing, many proinflammatory cytokine products are produced early in inflammation and will decrease with increasing time. ${ }^{31}$ The results also showed that the length of treatment can decrease the number of osteoclasts, as the activity of growth factor and anti-inflammatory cytokines arose.

The addition of S. hermanni to the application of bone graft from AG shells can reduce the number of osteoclasts more. This is because the hyaluronic acid content in S. hermanni can bind to CD44 which can increase anti-inflammatory cytokines, such as IL-10, which can regulate proinflammatory cytokines, resulting in a decrease in RANKL products in osteoblasts. ${ }^{3,29}$ This results in a decrease in osteoclasts count in groups receiving bone graft from a combination of AGSH.

This study was limited to the observation of anti-inflammatory cytokines (IL-10), but not proinflammatory cytokines (IL-1 $\beta$, IL-6, and TNF), because they were represented by observations of osteoclasts promoted by these proinflammatory cytokines. However, these preliminary results were promising and could be explored more for further studies with observations on biomarkers of osteogenesis.

\section{Conclusion}

Scaffold from a combination of AGSH was effective to enhance CD44 and IL-10 expression to decrease osteoclast in socket healing after tooth extraction in which the most effective concentration of S. hermanni was $0.8 \%$.

\section{Funding}

This study was supported by the National Research Program Grant (120/SP2H/LT/DRPM/IV/2017) and funded by the Indonesian Ministry of Research Technology and Higher Education.

\section{Conflict of Interest}

R.P.S. reports grants from Indonesian Ministry of Research Technology and Higher Education, during the conduct of the study. The other authors declare no conflict of interest.

\section{References}

1 Van der Weijden F, Dell'Acqua F, Slot DE. Alveolar bone dimensional changes of post-extraction sockets in humans: a systematic review. J Clin Periodontol 2009;36(12):1048-1058

2 Morjaria KR, Wilson R, Palmer RM. Bone healing after tooth extraction with or without an intervention: a systematic review of randomized controlled trials. Clin Implant Dent Relat Res 2014;16(1):1-20

3 Koh TJ, DiPietro LA. Inflammation and wound healing: the role of the macrophage. Expert Rev Mol Med 2011;13(23):e23

4 Kitaura H, Kimura K, Ishida M, Kohara H, Yoshimatsu $\mathrm{M}$, Takano-Yamamoto T. Immunological reaction in TNF- $\alpha$-mediated osteoclast formation and bone resorption in vitroand invivo.ClinDevImmunol2013;2013(181849):181849

5 Cao X. RANKL-RANK signaling regulates osteoblast differentiation and bone formation. Bone Res 2018;6(35):35

6 KohliSS, Kohli VS. Role of RANKL-RANK/osteoprotegerin molecular complex in bone remodeling and its immunopathologic implications. Indian J Endocrinol Metab 2011;15(3):175-181

7 Claudino M, Garlet TP, Cardoso CR, et al. Down-regulation of expression of osteoblast and osteocyte markers in periodontal tissues associated with the spontaneous alveolar bone loss of interleukin-10 knockout mice. Eur J Oral Sci 2010;118(1):19-28

$8 \mathrm{Kim} \mathrm{KH}$, Park JY, Park HS, et al. The influences of different ratios of biphasic calcium phosphate and collagen augmentation on posterior lumbar spinal fusion in rat model. Yonsei Med J 2017;58(2):407-414 
9 Mao K, Zhou F, Cui F, et al. Preparation and properties of $\alpha$-calcium sulphate hemihydrate and $\beta$-tricalcium phosphate bone substitute. Biomed Mater Eng 2013;23(3):197-210

10 Kresnoadi U, Rahayu RP, Ariani MD, Soesanto S. The potential of natural propolis extract combined with bovine bone graft in increasing heat shock protein 70 and osteocalcin on socket preservation. Eur J Dent 2020;14(1):31-37

11 Polo-Corrales L, Latorre-Esteves M, Ramirez-Vick JE. Scaffold design for bone regeneration. J Nanosci Nanotechnol 2014; 14(1):15-56

12 Dahiya P, Kamal R. Hyaluronic acid: a boon in periodontal therapy. N Am J Med Sci 2013;5(5):309-315

13 Schwertfeger KL, Cowman MK, Telmer PG, Turley EA, McCarthy JB. Hyaluronan, inflammation, and breast cancer progression. Front Immunol 2015;6(236):236

14 Litwiniuk M, Krejner A, Speyrer MS, Gauto AR, Grzela T. Hyaluronic acid in inflammation and tissue regeneration. Wounds 2016;28(3):78-88

15 Sari RP, Nurlaily I, Heryana RP, Fatmawati W, Ashrin MN. Combination of Anadara granosa shell-Stichopus hermanni gel on osteoblast-osteoclast and blood vessels in femur healing. J Int Dent Med Res 2020;13(2):770-777

16 Earl JS, Wood DJ, Milne SJ. Hydrothermal synthesis of hydroxyapatite. J Phys Conf Ser 2006;26:268-271

17 Balá P, Mechanochemistry in Nanoscience and Minerals Engineering. Berlin: Springer; 2010:103-132

18 You F, Li Y, Zuo Y, Li J. The Influence of $\gamma$-Ray Irradiation on the Mechanical and Thermal Behaviors of nHA/PA66 Composite Scaffolds. The Scientific World Journal $2013 ; 2013$ (162384):1-6

19 Tanideh N, Dehghani Nazhvani S, Mojtahed Jaberi F, et al. The healing effect of BioGlue in articular cartilage defect of femoral condyle in experimental rabbit model. Iran Red Crescent Med J 2011;13(9):629-633

20 Lin W, Xu L, Zwingenberger S, Gibon E, Goodman SB, Li G. Mesenchymal stem cells homing to improve bone healing. J Orthop Translat 2017;9:19-27

21 Aya KL, Stern R. Hyaluronan in wound healing: rediscovering a major player. Wound Repair Regen 2014;22(5):579-593
22 Ruffell B, Johnson P. The regulation and function of hyaluronan binding by CD44 in the immune system. Glycoforum: Science of Hyaluronan Today. 2009. Available at: http://www.glycoforum. gr.jp/science/hyaluronan/HA32/HA32E.html. Accessed June 6, 2018

23 Wolny PM, Banerji S, Gounou C, et al. Analysis of CD44hyaluronan interactions in an artificial membrane system: insights into the distinct binding properties of high and low molecular weight hyaluronan. J Biol Chem 2010;285(39): 30170-30180

24 Brancato SK, Albina JE. Wound macrophages as key regulators of repair: origin, phenotype, and function. Am J Pathol 2011;178(1):19-25

25 Peranteau WH, Zhang L, Muvarak N, et al. IL-10 overexpression decreases inflammatory mediators and promotes regenerative healing in an adult model of scar formation. J Invest Dermatol 2008;128(7):1852-1860

26 King A, Balaji S, Le LD, Crombleholme TM, Keswani SG. Regenerative wound healing: the role of interleukin-10. Adv Wound Care (New Rochelle) 2014;3(4):315-323

27 Vigetti D, Viola M, Karousou E, De Luca G, Passi A. Metabolic control of hyaluronan synthases. Matrix Biol 2014;35:8-13

28 Lesley J, Gál I, Mahoney DJ, et al. TSG-6 modulates the interaction between hyaluronan and cell surface CD44. J Biol Chem 2004;279(24):25745-25754

29 Mittal M, Tiruppathi C, Nepal S, et al. TNF $\alpha$-stimulated gene-6 (TSG6) activates macrophage phenotype transition to prevent inflammatory lung injury. Proc Natl Acad Sci U S A 2016;113(50):E8151-E8158

30 Takahashi N, Udagawa N, Suda T. Vitamin D endocrine system and osteoclasts. Bonekey Rep 2014;3:495

31 Vieira AE, Repeke CE, Ferreira Junior SdeB, et al. Intramembranous bone healing process subsequent to tooth extraction in mice: micro-computed tomography, histomorphometric and molecular characterization. PLoS One 2015; 10(5):e0128021 